\title{
PREDICTION OF REPAIR AND MAINTENANCE COSTS OF FARM TRACTORS BY USING OF PREVENTIVE MAINTENANCE
}

\author{
KHODABAKHSHIAN R. ${ }^{*}$ AND SHAKERI M. \\ "Department of Agricultural Machinery, Ferdowsi University of Mashhad, P.O. Box. 91775-1163 Mashhad, Iran \\ ${ }^{*}$ Corresponding author. E-mail: ra_kh544@stu-mail.um.ac.ir , Tel: (+98) 9153007648
}

Received: December 28, 2010; Accepted: January 21, 2011

\begin{abstract}
Estimates of tractor repair and maintenance costs are important for farm machinery replacement decisions and for general farm budgeting. The aim of this study was to provide a statistical analysis for the repair and maintenance costs of tractors in order to present an appropriate mathematical model based on farm records and to compare the derived repair cost function with other estimates. The study was also regarded as an exploratory exercise to assess the feasibility and form of a more comprehensive study on the using of PM in agriculture projects. In this context a study was conducted to predict accumulated R\&M costs of three typical tractors namely JD-3140, MF-285 and JD-3350 based on total working hours (X) by using Preventive Maintenance Program (PMP) in Kavardeh Agribusiness Company in Iran. To present the model, the stratified random sampling method on the basis of tractor age per year was used. The mean accumulated repair and maintenance costs and also the mean working hours (h/year) were calculated for per class separately. Calculated data was analyzed on the five models, linear, logarithmic, polynomial, power and exponential. Finally, it was found that power model gave better cost prediction with higher confidence and less variation than other models.
\end{abstract}

Keywords: Repair and Maintenance costs, Preventive Maintenance, Tractor, Iran.

\section{Introduction}

Today, tractor is one of the most important power sources in agriculture. Effect of tractor power on agriculture is considerable [8]. The use of modern technology during last decades resulted in rapid growth of farm production. Tractors and farm machinery are important samples of this modern technology $[3,14,15]$. The quality of inputs of mechanization and consequently land and labor productivity in both situations may differ considerably $[5,7,12]$. In the meantime, costs of owning and operating of farm machinery represent 35 to $50 \%$ of the costs of agricultural production when excluding the land [3]. The repair and maintenance cost (R\&M) is an important item in costs of owning and operation. In general, the costs other than those for repair and maintenance cost usually decrease with increasing usage, but the reverse is true with respect to R\&M costs. The cost of R\&M is usually about $10 \%$ of the total cost as the machine age increases the cost increases until it becomes the largest cost item of owning and operating of farm machines [12].

The replacement, repair or maintenance of a machine as it deteriorates over time has been studied in many contexts [13]. It is commonly agreed nowadays that preventive maintenance program can be very successful in improving equipment reliability while minimizing maintenance- related costs [16]. Preventive maintenance (PM) consists of actions that improve the condition of system elements before they fail [9]. Preventive maintenance is an action involving inspection, servicing, repairing or replacing physical components of machineries, plant and equipment by following the prescribed schedule. The PM activity does not affect the state of the element but ensures that the element is in operating condition. In this case the element remains 'as bad as old.' [6]. According to Khodabakhshian et al. [9], Preventive Maintenance is a planned maintenance activity of plant and equipment that is designed to improve machine life and avoid any unplanned maintenance activity.

Agricultural engineers have done many studies regarding R\&M of farm machines. Several studies were conducted in both developed and undeveloped countries either to develop models to determine the cost during a certain period or to get absolute numbers to represent owning and operating certain equipment $[5,10,17]$. Bower and Hunt [5] investigated around 1800 farmers in Illinois and Indiana and used R\&M costs data to develop models for predicting R\&M costs. Fairbanks et al. [7] working in Kansas collected R\&M costs data through search from 114 farm managers. At the end, accumulated R\&M costs were predicted using 
a power regression model based on cumulative usage hours of tractors. Ward et al. [17] obtained a power regression model for predicting accumulated R\&M costs based on accumulated usage hours for 63 forestry tractors in Ireland which gave very high cost estimates compared to other references. Morris [10] collected R\&M costs data of 50 tractors in Weasenham Farm Company in Norfolk and used them to obtain R\&M costs prediction model.

In Iran very limited studies have done on R\&M costs of tractors and farm machinery too. Almassi and Yeganeh [2] obtained an appropriate regression model for accurate prediction of accumulated R\&M costs based on accumulated usage hours for 213 tractors in Karoon Agro-Industrial Company in north of Khuzestan province. Also, Ashtiani-Eraghi et al. [4] conducted a study in order to derive a power regression model for predicting accumulated R\&M costs based on cumulative usage hours for 27 active tractors of two different models in Dasht-eNaz Agricultural Company in Mazandaran province. Moreover, Ajabshirchi et al. [1] obtained a polynomial regression model for predicting accumulated R\&M costs based on accumulated usage hours for 42 tractors working actively at Astan-e-Ghods-e-Razavi farms in Khorasan province.

As it can be found from literature review, despite an extensive research on R\&M costs of farm machinery, very limited published results on the R\&M costs of tractors are available. Hence, the aim of this study was to provide a statistical analysis for the repair and maintenance costs of tractors in order to present an appropriate mathematical model based on farm records and to compare the derived repair cost function with other estimates. The study was also regarded as an exploratory exercise to assess the feasibility and form of a more comprehensive study on the using of PM in agriculture projects.

\section{Materials and methods}

The experiment was performed at Kavardeh, $25 \mathrm{Km}$ away from Mashhad, Iran, with annual precipitation of $180 \mathrm{~mm}$ and Maximum and minimum absolute temp of $25^{\circ} \mathrm{C}$ and $-5^{\circ} \mathrm{C}$. Data for three typical tractors namely JD-3140, MF-285 and JD-3350 were obtained from Kavardeh Agribusiness Company which keep machinery records as part of a large management accounting system. For each tractor, information was sought on tractor characteristics and economic costs such as use of tractor each year, lubrication cost, filter cost, repairman wage, etc. Data over 20 years time period from 1994 to 2004 were collected. The mean working hours in per year was obtained, separately, for each tractor in per class, after stratifying samples. In addition, for each tractor, the mean annual repair and maintenance costs were separately calculated. In order to use PM in prediction of repair and maintenance of studied tractors several experiment consist of oil analyze and particle quantification was conducted on 10 oil samples of studied tractors during the working hours of them. Consequently, the collected data was compared with data provided in programming and control of project by the company after that following trend was carried out. Accumulated working hours for each tractor were calculated using Eq. 1.

$X_{m}=\sum_{i=1}^{m} x_{i}$

Where $X$ is the accumulated working hours for the class $m(h), m$ is the class number or age of the class tractors in unit year; $x$ is the mean yearly working hours for each tractor in per class (h/year). Also, for calculated of accumulated repair and maintenance costs Eq. (2) was used.

$$
Y_{m}=\sum_{i=1}^{m} y_{i}
$$

Where $Y$ is the accumulated repair and maintenance costs based on percent of list price, $y$ is the mean annual repair and maintenance costs each tractor in per class based on percent of list price. Based on that, ratio of the cumulative costs to the list price was estimated as the dependent variable and the cumulative working hours were obtained as independent variable. In order to determine mathematical model for the studied tractor, regression analysis was performed on the data by using sppss16.0 software. Five models were used to carry out regression analysis, which included the following:

$$
\begin{aligned}
& Y=a+b x \text { Linear } \\
& Y=a+b x+c x^{2} \text { Polynomial } \\
& Y=a e^{b z \quad \text { Exponential }} \\
& Y=a+\ln b x \text { Logarithmic } \\
& Y=a x^{b} \text { Power }
\end{aligned}
$$

The regression models having the highest coefficient of determination $\left(R^{2}\right)$ was selected as the best models for predicting actual R\&M costs trend. Finally, selected models were compared with reported models by other researchers.

\section{Results and discussion}

\subsection{Variation trend and costs of repair and} maintenance of studied tractors

The mean annual repair and maintenance costs related to all studied tractors were shown in Figure 1. As it can be found from this Figure, the tractor spare parts cost have the most share compared to other costs. The resulted values of spare parts cost for JD-3140, MF-285 and JD-3350 were $71.35 \%$, $67.95 \%$ and $69.72 \%$, respectively. The large share 
of tractor spare parts cost can be due to numerous factors such as making use of substandard tractor spare parts, unsuitable use of tractor, beginner driver, undesirable repairs and making use of tractor more than its optimum life that can be seen as the most important factor.

According to Figure 1, also, it is found that the repairman wage is the secondary importance. This value for JD-3140, MF-285 and JD-3350 were $14.54 \%, 18.39 \%$ and $16.3 \%$ of the total repair costs, respectively. The large share of repairman wage cost can be mainly due to high interest rate in country economic and subsequently to be increase rapidly wages. Similar results for spare parts cost and repairman wage have been revealed by Ajabshirchi et al. [1], Almassi and Yeganeh [2] and Rashidi et al. [11].

\subsection{Determination of appropriate mathematical model to predict repair and maintenance costs of studied tractors}

The obtained data from Baghain Agribusiness Company for a period of 20 years including annual use and cost were used to calculate the accumulated repair and maintenance cost and working hours. Then, these data were used to analysis and determine the repair and maintenance cost model. For instance, Table 1 provides information on mean accumulated working hours and mean accumulated R\&M costs as percent of list price for JD-3140 tractor.

Finally, the relation between the accumulated repair and maintenance cost and the accumulative working hours on the models of linear, logarithmic, Polynomial, Power and Exponential with correlation coefficient of related to itself for all studied tractors were determined. For case in point, Table 2 presents linear, Exponential, Power and Polynomial models as percent of list price $(Y)$ based on accumulated working hours (X) for JD-3140 tractor. Considering $F$ values, there is a significant correlation between $X$ and $Y$ variables in all four models. However, R2 values indicate that the Power and Polynomial models have higher conformity with actual data trend in comparison with the linear and Exponential models. In addition, in the most published studies in this field Power model gave better cost prediction with higher confidence and less variation than that of Exponential and logarithmic models $[1,2,11]$. Because of, easiness in calculations, the small difference between the correlation coefficients of Polynomial and Power models and using of Power model by other researchers, in the present study, Power model was suggested as final form of the repair and maintenance cost model.

Figure 2 illustrates the curves of predicted accumulated R\&M costs for all studied tractors based on accumulated working hours using the power model. It can be seen that the rate of accumulated R\&M costs for all studied tractors at earlier life time of them was low and fairly similar. However, trend of R\&M costs was rapidly increasing thereafter. The rate of increase was lowest for JD3350 tractor model and highest for MF-285 tractor model. Differences in increasing rate of R\&M costs may be attributed to the facts like quality in design and manufacturing, scarcity and higher cost of some spare-parts as compared to new price of tractor type, and also much frequent need for repair in some models. Steepness of accumulated R\&M costs curves for MF-285 and JD-3140 tractor models was higher than JD-3150 tractor model. This can be related to more frequent break-downs, inferior production technology, inherent deficiencies, and also incompatible field operations to their power and efficiencies. Similar results accumulated R\&M costs for four different tractors models based on accumulated usage hours have been revealed by Rashidi et al. [11].

\section{Conclusion}

Machinery ownership (fixed) and operating (variable) costs represent substantial portion of total production expenses. Machinery ownership costs usually include charges for depreciation, interest of investment (opportunity cost), taxes, insurance and housing facilities. Operating costs include repair and maintenance, i.e. spare-parts, wages and lubricants. In the meantime, the R\&M costs prediction models and agricultural machinery repair coefficients values are generally dependent on factors such as research method performance and time spans, number and type of samples under study, type of operation and working conditions, repair and maintenance management, quality of materials used, weather conditions and skill of operator. Results of this study showed that average R\&M costs per hour increased with machine age. These results also confirmed that there are considerable variations in R\&M costs among tractor models as well as individual ones. Also, based on the results obtained by this research, using Preventive Maintenance is more useful for replacement decisions than annual charge method. For circumstances similar to this study, estimates suggest that annual R\&M costs increase with age of tractor.

\section{Acknowledgments}

The authors would like to thank Ferdowsi University of Mashhad for providing the laboratory facilities and financial support.

\footnotetext{
References

[1] Ajabshirchi Y., Ranjbar I., Abbaspour M.H., Valizadeh M. and Rohani A. (2006) J. Agric. Sci., 16, 257-267.

[2] Almassi M. and Yeganeh H.R. (2002) Iranian J. Agric. Sci., 33, 707-716.
} 
[3] Anderson A.W. (1988) ASAE Paper No. 88-1057.

[4] Ashtiani-Eraghi A.R., Ranjbar I. and Toorchi M. (2006) J. Agri. Sci., 15: 101112.

[5] Bowers W. and Hunt D.R. (1970) Trans. of the ASAE, 13: 806-809.

[6] Bris R., Chatelet E. and Yalaoui F. (2003) Reliability Engineering and System Safety, 82: 247-255.

[7] Fairbanks G.E., Larson G.H. and Chung D.S. (1971) Trans. of the ASAE, 14: 98101.

[8] Gifford R.C. and Rijk A.G. (1980) Economic and Social Commission for Asia and the Pacific (ESCAP), Regional Network for Agricultural Machinery.

[9] Khodabakhshian R., Shakeri M. and Baradaran J. (2009) Asian International Journal of Science and Technology in Production and Manufacturing Engineering, 2:11-16.

[10] Moris J. (1988) J. Agric. Eng. Res. 41:191-200.

[11] Rashidi M., Ranjbar I., Gholami M. and Abbasi S. (2010) J. Agri. Sci., 4: 68-74.
[12] Rotz C.A. and Bowers W. (1991) ASAE Paper No. 91-1531.

[13] Rusell D., Meller I. and Kim S. (1996) J. Operational Res, 95: 577-591.

[14] Singh G. (1997) Central Institute of Agricultural Engineering, Nabi Bagh, Berasia Road, Bhopal, India.

[15] Singh G. and Chandra H. (2002) Central Institute of Agricultural Engineering, Nabi Bagh, Berasia Road, Bhopal, India.

[16] Sofia P. and George T. (2006) Euro. J. Operational Res, 5: 77-85.

[17] Ward S.M., McNulty P.B. and Cunney M.B. (1985) Trans. of the ASAE, 28: 1074-1076. 
Table 1- The accumulated repair and maintenance costs and working hours for JD-3140 tractor

\begin{tabular}{ccc}
\hline Age (Year) & Accumulated working hours & $\begin{array}{c}\text { Accumulated R\&M costs } \\
\text { (Percent of list price) }\end{array}$ \\
\hline 1 & 8.6535 & 4.86 \\
2 & 17.5122 & 11.03 \\
3 & 28.1628 & 16.27 \\
4 & 35.5227 & 21.43 \\
5 & 46.5432 & 27.32 \\
6 & 58.32 & 37.34 \\
7 & 71.2546 & 47.32 \\
8 & 78.7583 & 51.26 \\
9 & 84.7463 & 58.46 \\
10 & 97.4546 & 63.29 \\
11 & 101.2216 & 68.98 \\
12 & 107.3546 & 76.52 \\
13 & 117.2653 & 85.02 \\
14 & 125.8776 & 92.89 \\
15 & 136.3542 & 99.76 \\
16 & 145.3698 & 107.25 \\
17 & 153.7531 & 117.52 \\
18 & 164.5236 & 127.24 \\
19 & 174.5462 & 137.58 \\
20 & 183.4236 & 148.72 \\
\hline
\end{tabular}

Table 2- Description, coefficient, coefficient of determination $\left(R^{2}\right)$ and $F$ test results of five regression models obtained for JD-3140 tractor.

\begin{tabular}{lccclc}
\hline Model & $\mathrm{a}$ & $\mathrm{b}$ & $\mathrm{C}$ & $\mathrm{R}^{2}$ & $\mathrm{~F}$ \\
\hline Linear & -19.35 & 0.011 & - & 0.935 & $1822.410^{* *}$ \\
Logarithmic & -535.52 & 70.69 & - & 0.812 & $78.120^{* *}$ \\
Polynomial & 0.755 & 0.008 & $170 \times 10^{-7}$ & 0.998 & $4325.141^{* *}$ \\
Power & 0.003 & 1.175 & - & 0.994 & $5956.720^{* *}$ \\
Exponential & 16.245 & 0.025 & - & 0.91 & $178.542^{* *}$ \\
\hline
\end{tabular}




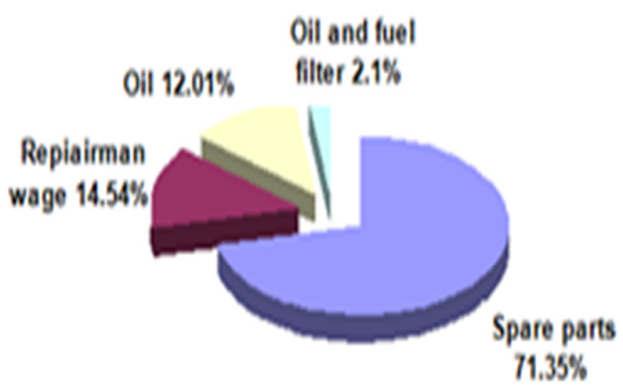

a

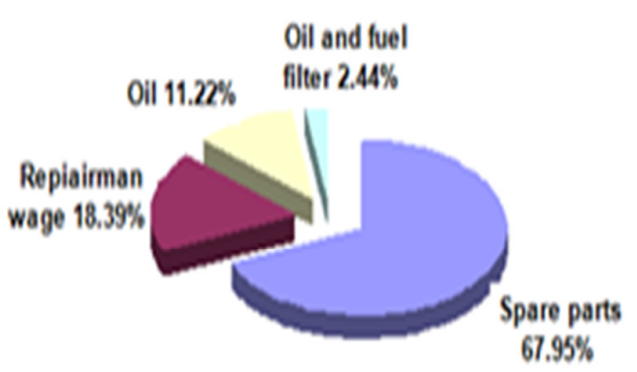

b

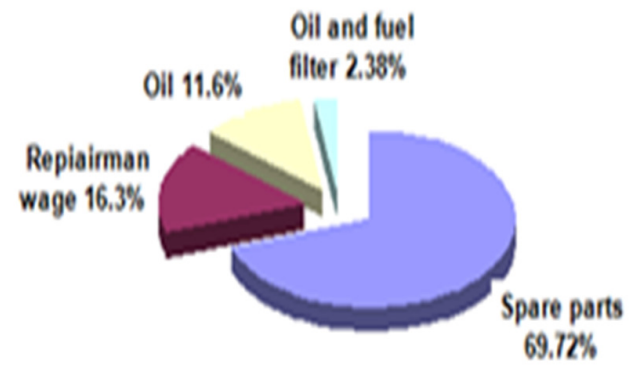

C

Fig. 1- The mean annual repair and maintenance costs for all studied tractors, (a) JD-3140; (b) MF-285; (c) JD3350

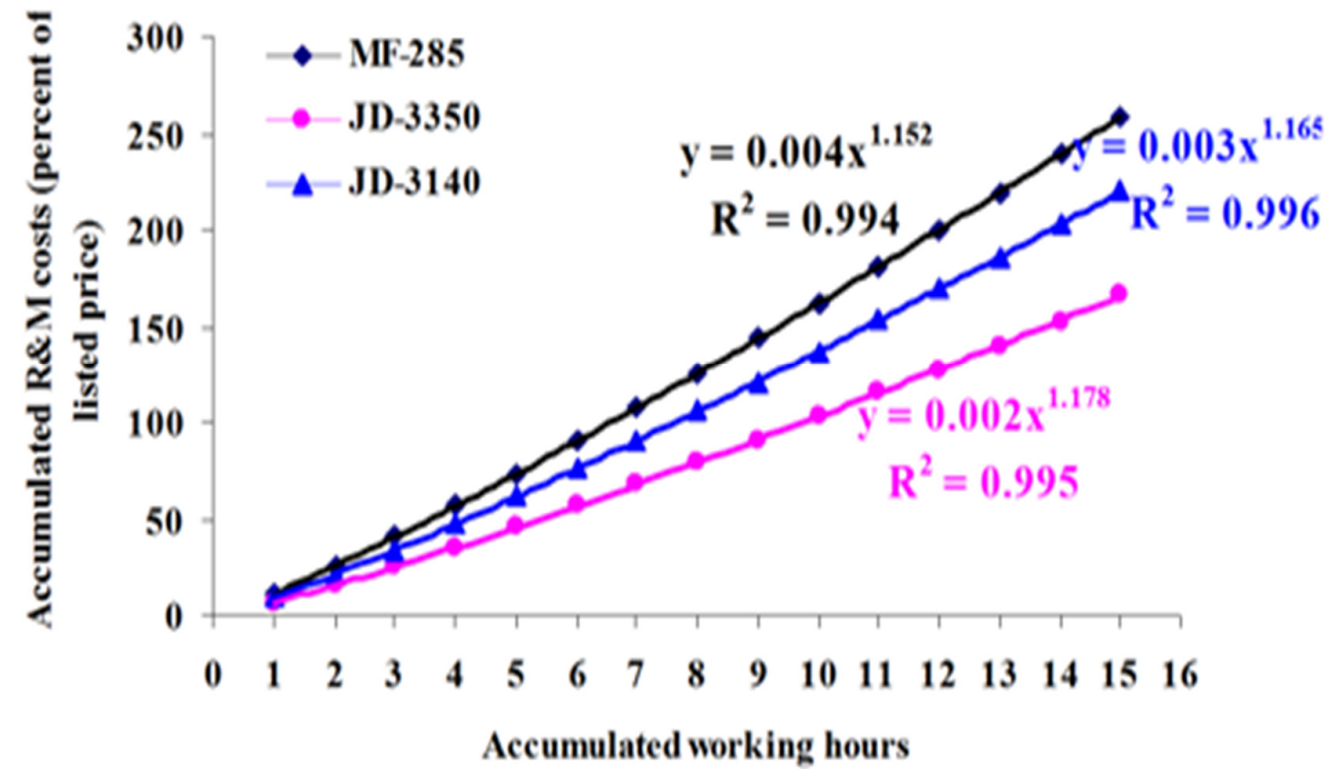

Fig. 2- Comparison of accumulated R\&M costs as percent of list price based on accumulated working hours on three studied tractors. 